\title{
FILOSOFIA JURÍDICA: CONSIDERAÇÕES SOBRE A COEXISTÊNCIA DO DIREITO NATURAL E O DIREITO POSITIVO
}

\author{
Fabiana Vergílio Souto \\ Universidade do Oeste Paulista - UNOESTE , Bacharela em Direito. E-mail: fabianavergiliosouto@hotmail.com
}

\begin{abstract}
RESUMO
Juspositivistas contestam a existência, legitimidade e validade do Direito Natural por estimá-lo como um ideal valorativo de justiça a ser alcançado.

Este estudo visa demonstrar a coexistência do Direito Natural e o Direito Positivo, apesar do antagonismo das teorias jusfilosóficas das quais são objetos, a saber, jusnaturalismo e juspositivismo, que embora superadas, ainda fundamentam a interpretação e aplicação das normas.

Por meio de pesquisa bibliográfica, observou-se que na atuação jurídica contemporânea, buscam-se além da norma escrita, conjecturas valorativas, de cunho principiológico, ético, moral, de modo a não reduzir o Direito às normas positivadas, que seria uma atuação exclusivamente juspositivista, nem limitar o Direito aos conteúdos axiológicos, operando d forma meramente jusnaturalista, pois este não se limita aos valores, tampouco às normas positivadas. Seja posto - Positivo, juridicamente válido - seja pressuposto - Natural, decorrente da própria natureza humana - o Direito é resultado de uma construção cultural e ideológica, conjunto de teorias que coexistem e norteiam a nomogênese e a subsunção. Conclui-se que o Direito Positivo não exclui o Direito Natural, pois este é abarcado por aquele, seja na elaboração da norma, seja na aplicação desta.
\end{abstract}

Palavras-chave: Direito Natural. Direito Positivo. Jusfilosofia. Jusnaturalismo. Juspositivismo.

\section{LEGAL PHILOSOPHY: CONSIDERATIONS ON THE COEXISTENCE OF NATURAL LAW AND POSITIVE LAW}

\begin{abstract}
Juspositivists contest the existence, legitimacy and validity of Natural Law for estimating it as an ideal value of justice to be achieved.

This study aims at demonstrating the coexistence of Natural Law and Positive Law, despite the antagonism of the philosophical theories of which are objects, namely, Natural Law and juspositivism, which, although surpassed, still support the interpretation and application of norms.

Through bibliographic research, it was observed that in contemporary legal practice, in addition to the written norm, valuative conjectures are sought, of a principiological, ethical, moral nature, so as not to reduce the Law to the established norms, which would be an exclusive action juspositivist, nor to limit the Law to axiological contents, operating in an eminently jusnaturalist way, as this is not limited to values, nor to positive norms. Be positive - Positive, legally valid - Be presupposed - Natural, due to human nature itself - Law is the result of a cultural and ideological construction, a mixture of theories that coexist and guide nomogenesis and subsumption. It is concluded that Positive Law does not exclude Natural Law, as it is covered by it, either in the elaboration of the norm, or in its application.
\end{abstract}

Keywords: Jusnaturalism. Juspositivism. Legal Philosophy. Natural Law. Positive Law. 


\section{INTRODUÇÃO}

Juspositivistas se voltam contra o

Direito Natural, objeto do jusnaturalismo, argumentando em detrimento da teoria, explorando a existência de um conjunto de princípios éticos que transcende a solenidade textual e que algo só é justo se realmente estiver de acordo com tais princípios. Juspositivistas separam a moral que envolve o valor justiça admitindo como válido e adequado exclusivamente o que é instituído pelo Estado.

O jusnaturalismo e o juspositivismo são duas grandes conjunturas jusfilosóficas que, de acordo com a história, posicionaram-se em ângulos antagônicos, mas que guardam afinidades, e apesar de superadas, ainda são parâmetros para efetiva operação do Direito.

Por meio da pesquisa exploratória, essencialmente bibliográfica e de natureza qualitativa, enfatizando obras e autores renomados, objetivou-se demonstrar a coexistência histórica do Direito Natural e o Direito Positivo.

\section{CONTRAPOSIÇÃO OU COEXISTÊNCIA ENTRE DIREITO NATURAL E DIREITO POSITIVO}

A teoria do Direito Natural é o mais antigo ensaio da compreensão teórica abarcante do fenômeno jurídico. É certo que as inquietações acerca da doutrina do jusnaturalismo têm um longo trajeto histórico e se individualizam por ser uma das posturas teóricas mais enaltecidas no curso do pensamento jurídico. De tal modo, é plausível afirmar que, a despeito de todas as oposições que Ihe foram perpetradas, a doutrina do Direito Natural foi conservada durante um extenso período como uma das problemáticas fundamentais do conhecimento jurídico. ${ }^{1}$

Os jusnaturalistas sustentam que 0 Direito Natural comporta o Direito Positivo, constituindo elemento basilar à sua validade, observando a essência de valores morais e existenciais, que são inerentes ao homem e ao comportamento social, universalmente abrangente. Essa escala de valores é, nesse ângulo de visão, antecedente a qualquer comando jurídico ou norma positivada (GARCIA, 2010).

\footnotetext{
${ }^{1}$ A intenção do jusnaturalismo é demonstrar diretrizes jurídicas universais e imutáveis que não poderão ser contestadas empiricamente, como normalmente se crê, só em face da consideração de existirem diversas acepções jurídicas que variam em relação aos diferentes povos e às diferentes épocas.
}

Embora se posicione como uma corrente de pensamento é possível notar a existência de gradações distintas no que se alude à preparação da estrutura substancial que integra seu sustentáculo teórico. Os entendimentos não são inteiramente correlativos, mesmo entre os partidários de tal corrente.

O principal direcionamento sobre o qual a corrente se estrutura é a afirmação da existência de normas, não fundamentalmente positivadas, ${ }^{2}$ internalizadas pelo homem diante do pressuposto de equidade (REALE, 2002).

Consiste em uma corrente de pensamento multidisciplinar, construída sob a égide jurídica, filosófica e teológica, ainda que seu objeto central de averiguação seja o Direito.

O jusnaturalismo alastra a imagem do Direito ideal, todavia passível de efetivação, podendo ser posto em prática. Do mesmo modo, não se trata de um conjunto de normas ilusórias ou fantasiosas, ou de expectativas compostas por elementos intangíveis, mas sim, alcançáveis.

Bobbio (1990, p. 11) discorre sobre o jusnaturalismo,

[...] como doutrina
segundo a qual existem
leis não postas pela
vontade humana - que
por isso mesmo precedem
à formação de todo grupo
social e são reconhecíveis
através da pesquisa
racional - das quais
derivam, como em toda e
qualquer lei moral ou
jurídica, direitos e deveres
que são, pelo próprio fato
de serem derivados de
uma lei natural, direitos e
deveres naturais.

O Direito Natural surge de fenômenos sociais respeitáveis e é percebido em episódios que aclaram os valores de maior consideração nos fatos sociais. Independe de opiniões de qualquer pessoa ou governante. Por esta razão, esta forma de direito não perde força com o tempo e tem incidência em numerosos espaços, não podendo ser adstrito, salvo pela própria coletividade vivente deste direito. O Direito

\footnotetext{
${ }^{2}$ O jusnaturalismo afirma haver uma ligação íntima entre Direito e moral, com um conjunto de princípios

universalmente válidos, como o direito à vida, à liberdade, segurança, enfim, que não decorrem de norma emanada pelo Estado, sendo típicos da natureza humana.
} 
Positivo, por sua vez, é cunhado pela organização política (HERVADA, 2008, p. 338).

Segundo o autor supracitado, acerca da natureza de cada um, conforme sua interpretação feita diante da concepção aristotélica,

[...] o direito natural e o direito positivo são verdadeiros direitos. Tanto o justo natural como o justo positivo são espécies ou tipos de direito. Ambos fazem parte igualmente do direito vigente de uma polis (politikón díkaion). É, então, claro que para Aristóteles 0 direito natural é um direito verdadeiro, um tipo de direito vigente, junto com outro tipo, que é o direito positivo. $O$ direito natural não é, portanto, um princípio abstrato, uma ideia ou ideal, um valor ou coisa semelhante; é simplesmente um direito (uma coisa devida em justiça), uma espécie ou tipo particular de direito (HERVADA, 2008).

Assinala Tércio Sampaio Ferraz que "positivar" é ato de uma autoridade posta e hegemônica - no sentido de dominante - que ativa sua vontade, de maneira soberana, deliberando por comportamentos proibidos ou permitidos. É o ato volitivo do poder que cria a positivação e baliza o Direito Positivo, posição que perante a visão jusnaturalista, não é adequada dada a existência da autorização ou da proibição em uma prática anterior à criação da própria autoridade instituidora, fato que atém o Direito ao que é ou não lei, acarretando um isolamento entre a realidade fática e o meio jurídico (FERRAZ, 2002).

O jusnaturalismo parte do princípio antidemocrático de que há um teor de justiça apriorístico em relação ao juspositivismo, ${ }^{3}$ o qual precisa submeter-se a esses princípios e deve ser atribuído a todos os desviantes e recalcitrantes (VIEHWEG, 2006).

\footnotetext{
${ }^{3}$ Segundo esta corrente do pensamento jurídico, uma lei para ser lei deve estar de acordo com a justiça. Jusnaturalistas entendem que o valor justo é inerente a tudo que existe em termos de ideal do bem comum.
}

$\mathrm{Na}$ antiguidade, esse corpo de normas abrangidas pelo jusnaturalismo era avaliado como verdadeiro, imutável e universal; ou seja, estático no tempo e no espaço. Esta caracterização, contudo, desconsiderava o progresso dos grupos sociais, resultante do dinamismo histórico e cultural.

A valoração é função da capacidade apreciativa da consciência humana. A própria moral concebe uma apreciação instável, expressivamente influenciada pelos costumes, instituições e culturas de modo geral. As sociedades são resultados históricos, alicerces do Direito e demais regras (FERRAZ, 2002).

Essa variante do Direito origina-se de fontes naturais e irrefutavelmente valorativas. Sob esse prisma, não é raro o ilícito jurídico se enlear com questões de ordem moral, visto que atenta contra o estruturalismo social fundado e perfilhado como padrão de conduta, autenticado no subconsciente dos indivíduos.

É admissível definir o Direito Natural como uma doutrina jurídica que entende que o Direito deve ser objeto de uma valoração que tem como referência um sistema superior de normas ou de princípios que the conservam a validade, sem os quais o Direito perde sua finalidade (FERRAZ, 2002).

Em decorrência desta acepção, destacam-se as imediatas características na doutrina do Direito Natural:

a) a legislação em vigor deve ser considerada a partir de determinados conteúdos superiores;

b) estes conteúdos superiores possuem como fonte uma determinada categoria universal e imutável, geralmente atrelados ao ideal de justiça;

c) estes conteúdos devem sempre prevalecer sobre as disposições formais da legislação em vigor.

A diferença entre o jusnaturalismo e juspositivismo aparenta depender da referência de valor da qual se acomoda o sujeito na explicação e compreensão da norma. Realmente, as regras do Direito Natural são abrigadas pela razão e as do Direito Positivo são abarcadas pelo conhecimento da norma e coercibilidade.

O Direito Positivo corresponde àquele legislado pelo homem, independentemente do tempo e espaço, sendo essencialmente heterônomo, ou seja, imposto pela força estatal (NADER, 2011). 
A expressão "positivismo jurídico" não resulta de "positivismo", na acepção filosófica do termo, embora no século passado tenha havido considerável relação, levando em conta que alguns positivistas jurídicos eram igualmente positivistas, na acepção da escola fundada por Comte. Na verdade, o termo deriva da locução "Direito Positivo" em contrariedade àquela de "Direito Natural".

Fundamentalmente, o Direito Positivo corresponderia às normas de conduta, sendo legisladas ou mesmo oriundas da cultura de determinada sociedade, ou seja, costume, que objetivam tornar possível e adequado o convívio humano.

Paulo Dourado de Gusmão define o juspositivismo como histórico e objetivamente estabelecido, efetivamente observado, passível de ser fixado coercitivamente, encontrado em leis, código, costumes, resoluções, decretos, decisões dos tribunais etc. (GUSMÃO, 2000).

Bobbio (1995, p. 119), ensina em sua obra:

\begin{abstract}
A corrente doutrinária do juspositivismo entende $o$ termo "direito positivo" de maneira bem específica, como direito posto pelo poder soberano do Estado, mediante normas gerais e abstratas, isto é, como "lei". Logo, o positivismo jurídico nasce do impulso histórico para a legislação, se realiza quando a lei se torna a fonte exclusiva ou, de qualquer modo, absolutamente prevalente - do direito, e seu resultado último é apresentado pela codificação.
\end{abstract}

No tocante à gênese da noção de legislação como processo fundamental na formação do Estado moderno, se inicia no século XII e XIII, remetendo ao período histórico em que se compôs a doutrina canonista.

O positivismo nasce a partir da negação da teoria jusnaturalista. Se os jusnaturalistas persistem que a autoridade das normas jurídicas seria emanada de uma ordem superior, certo tipo de ente transcendental para além do Direito, os juspositivistas prossegue com a ideia de que a autoridade das normas jurídicas pode ser aclarada levando em consideração fatos sociais (GARCIA, 2010).

A procura por diretrizes fundamentais, que sustentassem as teorias em prol da codificação da legislação, assim como decorreu ao longo do desenvolvimento do Estado moderno, admite-se o realce de duas.

A primeira diretriz estaria relacionada à prevalência dispensada à lei, que manifesta a compreensão de Direito como ordenamento lógico da sociedade. Esse ordenamento não poderia surgir de comandos singulares e ocasionais, porém deveria fluir somente de normas gerais e lógicas, que demonstrassem coerência, assentadas pelo poder soberano da própria sociedade, legítima para tal ato (BOBBIO, 1995, p. 119)

A segunda diretriz estaria relacionada à supremacia da lei como fonte do direito que teria ascendência do próprio desígnio humano de transformar a sociedade. Sobre isso, expressa Bobbio (1995, p.20):

[...] como o homem pode controlar a natureza através do propósito de suas leis, assim ele pode transformar a sociedade através da renovação das leis que a regem; mas para que isso seja possível, para que o direito possa modificar as estruturas sociais, é mister que seja posto conscientemente, segundo uma finalidade racional; é mister, portanto, que seja posto através da lei. $O$ direito consuetudinário não pode, de fato, servir a tal finalidade, porque é inconsciente, irrefletido, é um direito que exprime e representa a estrutura atual da sociedade e, consequentemente, não pode incidir sobre esta para modificá-la; a lei, em lugar disto, cria um direito que exprime a estrutura que se quer que a sociedade assuma. 0 costume é uma fonte passiva e a lei uma fonte ativa do direito. (sic) 
Assim, o ato de legislar que somente o

Estado pode deter, seria instrumento absolutamente necessário para equilibrar o convívio humano, contendo o caos do direito primitivo e dando ao ente estatal uma ferramenta adequada que permitisse a intervenção nas relações sociais.

Conveniente é o apontamento de Larenz (2005, p. 46) sobre a relatividade moral e a abstenção valorativa atribuída ao positivismo:

[...] a humildade cientifica do positivista não exclui que ele tenha para si valores ou exigência éticas; só que os remete para o mundo das crenças pessoais e das convicções morais sobre os quais, do seu ponto de vista não é possível um enunciado científico. Ele não nega, por exemplo, que a exigência da justiça valha para a consciência de cada um, mas é de opinião de que ela não é passível de conhecimento científico e de que, portanto, não constitui um princípio de ciência juspositivista.

De tal modo, para a doutrina do positivismo jurídico, a apreciação de justiça deve ser diferenciada do conceito de validade, sendo esta dispensável àquela. Para o Direito Natural as prescrições só poderiam ser ponderadas como válidas quando fossem justas, ou seja, direito válido é direito justo.

Conforme Reale (2002, p. 65):

Onde quer que haja um fenômeno jurídico, há, sempre necessariamente, um fato subjacente (fato econômico, geográfico, demográfico, de ordem técnica, etc.); um valor, que confere determinada significação a esse fato, inclinando ou determinando a ação dos homens no sentido de atingir ou preservar certa finalidade ou objetivo; e finalmente, uma regra ou norma, que representa a relação ou medida que integra um daqueles elementos ao outro, o fato ao valor. Tais elementos ou fatores (fato, valor e norma) não existem separados um dos outros, mas coexistem numa unidade concreta. (sic)

Para o positivismo, a legitimidade do direito independe de ideais de justiça, sendo o direito válido o direito posto, decorrendo disso a possibilidade de advir a legitimidade até mesmo do direito injusto. Em resumo, toda conduta, justa ou injusta, pode ser substância de uma norma jurídica, porque o que faz uma regra jurídica não é o seu teor, e sim a sua concepção ou a sua efetivação na realidade fática.

Metodologicamente, verifica-se que genuína contraposição há entre o juspositivismo e o jusnaturalismo, visto que a proposição primordial do juspositivismo, que também se subdivide em outras teorias derivadas, é a de que o único Direito admitido é o Positivo, de modo a ser justo somente o que é resguardado por norma juridicamente válida.

O Direito Natural se manifesta de variadas formas na operação do Direito contemporâneo, como na aplicação da analogia, na consideração da equidade, dos costumes e dos princípios gerais do Direito para fins de subsunção e até mesmo por meio do emprego de doutrinas atualizadas que reconstroem novos entendimentos acerca de normas, por vezes, defasadas ante o dinamismo social.

Dizer que o homem é um ser racional é o mesmo que dizer que é um ser que se dirige. A atuação, portanto, implica sempre uma valoração. Todo valor, por conseguinte, é uma abertura para o dever ser. Quando se fala em valor, fala-se sempre em solicitação de comportamento ou em direção para o atuar.

Valor e dever ser implicam-se e exigem-se reciprocamente. Sem a ideia de valor, não temos a compreensão do dever ser. Quando o dever ser se origina do valor, e é recebido e reconhecido 
racionalmente como motivo da atuação ou do ato, temos aquilo que se chama um fim (REALE, 2002, p. 380).

Os fatos estimados como moralizadores, compostos por valores positivos, motivam a feitura das normas, como uma força motriz.

Observando-se os fatos sociais é possível coligir os valores estimados por determinada sociedade. Os valores refletem a influência social nas normas jurídicas, que provocam no legislador a nomogênese, positivando um valor que antes, apesar de cultuado, era abstrato.

Destarte, o Direito Natural amolda a crítica jurídica, servindo como procedimento de conhecimento e construção teórica do Direito Positivo, oferecendo a este, diretrizes de ordem axiológica.

\section{CONCLUSÃO}

Por meio desta pesquisa, com fulcro em pesquisa bibliográfica, observa-se que Direito Natural e Direito Positivo não são necessariamente adversos, pois apesar das premissas distintas das correntes jusfilosófica das quais são objetos, ambos podem coexistir, pois, o Direito Natural é abarcado pelo Direito Positivo, de modo a servir-lhe de substância propulsora na nomogênese e subsídio hermenêutico na subsunção.

Para o jusnaturalismo, o Direito não está limitado àquele positivado e vigente, pois defende a existência de um Direito originário da própria e preexistente natureza humana.

À vista disso, colige-se a existência do Direito Positivo e do Direito Natural em harmonia, uma vez que aquele encontra neste a chave para resolução da incompatibilidade conflituosa de normas positivadas. Seja posto Positivo, juridicamente válido - seja pressuposto - Natural, decorrente da própria natureza humana - o Direito é resultado de uma construção cultural e ideológica, mescla de teorias que coexistem e norteiam a nomogênese e a subsunção.

\section{REFERÊNCIAS}

BOBBIO, N. Liberalismo e Democracia. $3^{\circ} \mathrm{Ed}$.

Tradução Marco Aurélio Nogueira. São Paulo:

Editora Brasiliense, 1990. FERRAZ JÚNIOR, T. S.
Introdução ao estudo do direito: técnica, decisão, dominação. 3. ed. São Paulo: Atlas, 2002.

GARCIA, G. F. B. Introdução ao estudo do direito. São Paulo: Método, 2010.

GUSMÃO, P. D. Introdução ao estudo do direito. Rio de Janeiro: Forense, 2000.

HERVADA, J. Lições propedêuticas de filosofia do direito. Revisão técnica Gilberto Callado de Oliveira. São Paulo: Martins Fontes. 2008.

LARENZ, K. Metodologia da ciência do direito. Trad. José Lamego. 4. ed. Lisboa: Fundação Calouste Gulbenkian, 2005.

NADER, P. Introdução ao estudo do direito. Rio de Janeiro: Forense, 2011.

REALE, M. Filosofia do direito. 20. ed. São Paulo: Saraiva, 2002a.

REALE, M.Lições preliminares do direito. 26. ed. São Paulo: Saraiva, 2002b.

VIEHWEG, T. Modernidade e direito. In: ADEODATO, J. M. Ética e retórica: para uma teoria da dogmática jurídica. São Paulo: Saraiva, 2006. 